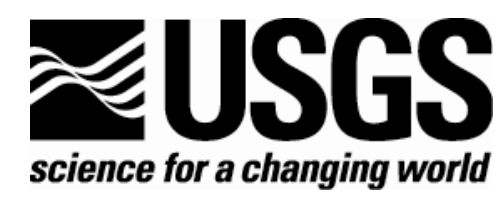

\title{
Magnetic Properties of Sediments in Cores BL96-1, -2, and -3 from Bear Lake, Utah and Idaho
}

By Joseph G. Rosenbaum

Open-File Report 2005-1203

U.S. Department of the Interior

U.S. Geological Survey 


\section{U.S. Department of the Interior \\ Gale A. Norton, Secretary}

\section{U.S. Geological Survey \\ Charles G. Groat, Director}

\section{U.S. Geological Survey, Reston, Virginia 2005}

For sale by U.S. Geological Survey, Information Services

Box 25286, Denver Federal Center

Denver, CO 80225

For more information about the USGS and its products:

Telephone: 1-888-ASK-USGS

World Wide Web: http://www.usgs.gov/

Any use of trade, product, or firm names in this publication is for descriptive purposes and does not imply endorsement by the U.S. Government.

Although this report is in the public domain, permission must be secured from the individual copyright owners to reproduce any copyrighted material contained within this report.

This report has not been reviewed for stratigraphic nomenclature.

Suggested citation:

Rosenbaum, J.G., 2005, Magnetic Properties of Sediments in Cores BL96-1, -2, and -3 from Bear Lake, Utah and Idaho: U.S. Geological Survey Open-File Report 2005-1203, 13p.

Prepared by the U.S. Geological Survey in Denver, Colorado (http://climchange.cr.usgs.gov/) 


\title{
Magnetic Properties of Sediments in Cores BL96-1, -2, and -3 from Bear Lake, Utah and Idaho
}

\author{
By Joseph G. Rosenbaum
}

\section{Introduction}

As part of an ongoing study to derive records of past environmental change from lake sediments in the western United States, a set of three cores was collected from Bear Lake, Utah, in 1996. The three cores, BL96-1, -2, and -3, form an east-west profile and are located in about 50, 40 , and $30 \mathrm{~m}$ of water, respectively. The cores range in length from $4 \mathrm{~m}$ to $5 \mathrm{~m}$, but because sediments thin markedly to the west (Colman, 2005) the maximum age of sediments penetrated increases from east to west. Together the cores provide a record from the last glacial period through the Holocene. This report presents magnetic property data acquired from these cores.

\section{Methods}

\section{Coring and Sampling}

Three cores (BL96-1, -2 and -3) were taken with a Kullenburg-type piston corer. The inner diameter of the corer's plastic liner was $7 \mathrm{~cm}$. The cores were cut lengthwise. One-half of each core was preserved and logged (Smoot, 2005), the other half was cut into samples at $1-\mathrm{cm}$ intervals. Samples were then subdivided for a variety of analyses including measurements of magnetic properties.

\section{Magnetic Property Measurements}

Magnetic properties reflect types, amounts, and magnetic grain sizes of magnetic minerals in geologic materials (Thompson and Oldfield, 1986; Verosub and Roberts, 1995). For sediments lacking in magnetite, hematite, and other strongly magnetic minerals, magnetic susceptibility (MS) reflects the content of paramagnetic minerals (for example, biotite and pyrite) and of diamagnetic materials (for example, calcite, quartz, opaline silica, and water). Magnetic susceptibility, anhysteretic remanent magnetization (ARM), and isothermal remanent magnetization (IRM) commonly reflect the content of ferrimagnetic minerals (for example, magnetite, titanomagnetite, and greigite) but differ in their sensitivity to variations in magnetic grain size (Dunlop and Özdemir, 1997). Hard IRM (HIRM) is a measure of high-coercivity minerals (for example, hematite and goethite). For ferrimagnetic grains large enough to carry remanent magnetization $(\geq 0.03$ 
$\mu \mathrm{m})$, MS has a weak dependence on magnetic grain size, increasing somewhat as grains increase from single domain to multidomain. For such remanence-carrying grains, both IRM and ARM decrease with increasing grain size so that large multidomain grains contribute relatively little in comparison to smaller grains. In comparison to IRM, ARM varies more strongly for very small grains $(<1 \mu \mathrm{m})$, with ARM being particularly strong for magnetite grains with diameters on the order of $0.1 \mu \mathrm{m}$ or smaller. Because of the differing dependence of these magnetic properties on the size of ferrimagnetic grains, the ratios ARM/MS and IRM/MS provide convenient qualitative measures of "magnetic grain size" (with higher values indicating finer sizes).

Samples were placed in nonmagnetic $3.2-\mathrm{cm}^{3}$ plastic boxes. Anhysteretic and isothermal remanent magnetizations (ARM and IRM) were measured with a high-speed spinner magnetometer. ARM was imparted using an alternating field with a peak intensity of 0.1 Tesla (T) and a bias field of 0.1 milliTesla (mT). After measurement of ARM, IRM was first imparted in a $1.2 \mathrm{~T}$ field $\left(\mathrm{IRM}_{1.2 \mathrm{~T}}\right)$ and then in the opposite direction in a field of $0.3 \mathrm{~T}\left(\mathrm{IRM}_{-0.3 \mathrm{~T}}\right)$. Hard isothermal remanent magnetization (HIRM) and the S-parameter (King and Channel, 1991) are given by:

$\begin{array}{ll} & \mathrm{HIRM}=\left(\mathrm{IRM}_{1.2 \mathrm{~T}}-\mathrm{IRM}_{-0.3 \mathrm{~T}}\right) / 2, \\ \text { and } & \mathrm{S}=\mathrm{IRM}_{-0.3 \mathrm{~T}} / \mathrm{IRM}_{1.2 \mathrm{~T}} .\end{array}$

$$
\mathrm{S}=\mathrm{IRM}_{-0.3 \mathrm{~T}} / \mathrm{IRM}_{1.2 \mathrm{~T}} \text {. }
$$

Samples then were dried and weighed. Dry bulk densities were calculated by dividing the dry mass of each sample by the standard volume of the sample boxes (3.2 $\mathrm{cm}^{3}$ ). MS values, which were acquired after drying to eliminate the diamagnetic effects of pore water, were measured in both $600-$ and $6,000-\mathrm{Hz}$ alternating fields with amplitudes of about $0.1 \mathrm{mT}$. The MS readings were corrected for the diamagnetic effect of sample boxes. All magnetic properties, which are tabulated in the appendices 1, 2, and 3, are given in International System (SI) mass units and are based on dry sample masses.

The most common ferrimagnetic minerals in detrital materials are magnetite and titanomagnetite, and the most common high-coercivity mineral is hematite. For convenience, ferrimagnetic minerals such as magnetite, titanomangetite, and maghemite, will be referred to herein as magnetite. Similarly high-coercivity magnetic phases will be referred to as hematite.

\section{Results and Discussion}

Sediments from the three cores form a composite section extending from about 32 cal. kyr through the Holocene (Colman and others, 2005). The section can be divided into lower and upper units on the basis of mineral content (Dean and others, 2005). The lower unit is composed of siliciclastic sediment containing about 75 percent quartz, 10 percent carbonate (because carbonate rocks are common in the catchment, this carbonate may be largely detrital), and lesser amounts of other components (that is, other detrital minerals and biogenic silica). Most of the lower unit is red, but the upper $10 \mathrm{~cm}$ in core BL96-2 are greenish, and the unit grades upward from red to yellowish above $65 \mathrm{~cm}$ in core BL96-3. In contrast, the younger (upper) unit contains abundant endogenic carbonate (40 - 75 percent) and less detrital material (quartz content 25 - 35 percent), and is gray throughout. The upper carbonate-rich unit makes up all of core BL96-1 (fig. 1) 
and the upper $2.95 \mathrm{~m}$ of core BL96-2 (fig. 2). The lower unit extends from about $3.20 \mathrm{~m}$ to the bottom of core BL96-2 and makes up all but the upper $0.40 \mathrm{~m}$ of core BL96-3 (fig. 3 ). In core BL96-2, there is a 0.25 -m-thick transitional interval between the upper and lower units in which quartz content progressively decreases (by a factor of about 2, see Dean and others, 2005) and calcite increases. This transitional zone is absent from core BL96-3. In addition, the thin upper unit in this core probably contains gaps of unknown number and duration and, therefore, will be largely ignored in the following discussion.

Well-defined variations in magnetic properties occur between and within the upper and lower units (figs. 1 - 3). These variations reflect the types, quantities, and magnetic grain sizes of magnetic minerals. In general, such variations may arise in several ways including dilution, changes in provenance, and variations in the type and degree of alteration. Differences in the amount of dilution of magnetic minerals are produced by changes in the concentrations of diamagnetic material (for example, carbonate minerals and biogenic silica). Such changes produce similar changes in parameters that reflect concentrations of magnetic minerals (that is, MS, ARM, IRM, and HIRM) but do not affect values that reflect relative amounts of magnetic minerals (for example, S) or magnetic grain size (for example, ARM/MS and IRM/MS). Changes in provenance will be reflected in sediment magnetic properties if the areas from which detrital material is derived have significantly different magnetic mineralogies. Such shifts in source area can produce changes in the absolute concentrations of magnetic minerals, and/or relative amounts of magnetic minerals, and/or magnetic grain size. Alteration of magnetic minerals can occur in either an oxidizing environment (for example, due to weathering) or in a reducing environment (for example, after deposition). In an oxidizing environment the concentration of magnetite will decrease, the concentration of hematite will remain the same or increase, and magnetic grain size will increase as finer grain sizes are preferentially destroyed (Rosenbaum and Reynolds, 2004). Both magnetite and hematite are readily destroyed in reducing environments. If a secondary ferrimagnetic mineral such as greigite is not formed by such alteration, then concentration parameters will decrease and magnetic grain size will increase. If alteration produces greigite, the effect on concentration parameters is uncertain, but IRM/MS is likely to be very large (Reynolds and others, 1998; Reynolds and others, 1999).

\section{Lower Unit}

Changes in provenance, dilution by endogenic calcite and aragonite, and postdepositional alteration combine to produce the observed magnetic property variations. Within the lower unit in core BL96-3, MS, ARM, IRM, and HIRM display well-defined, quasi-cyclical variations (fig. 3). Below $0.79 \mathrm{~m}$ in core BL96-3 there is a strong positive relation among measures of magnetite content (fig. 3) and a negative relation between magnetite content and hematite content (i.e., HIRM, fig. 4). Because hematite content increases as magnetite content decreases, the observed variations cannot be produced by variable amounts of dilution nor by postdepositional alteration in a reducing environment. The lack of significant changes in magnetic grain size below $0.79 \mathrm{~m}$ (fig. 3) further supports the interpretation that the observed variations were not produced by alteration. 


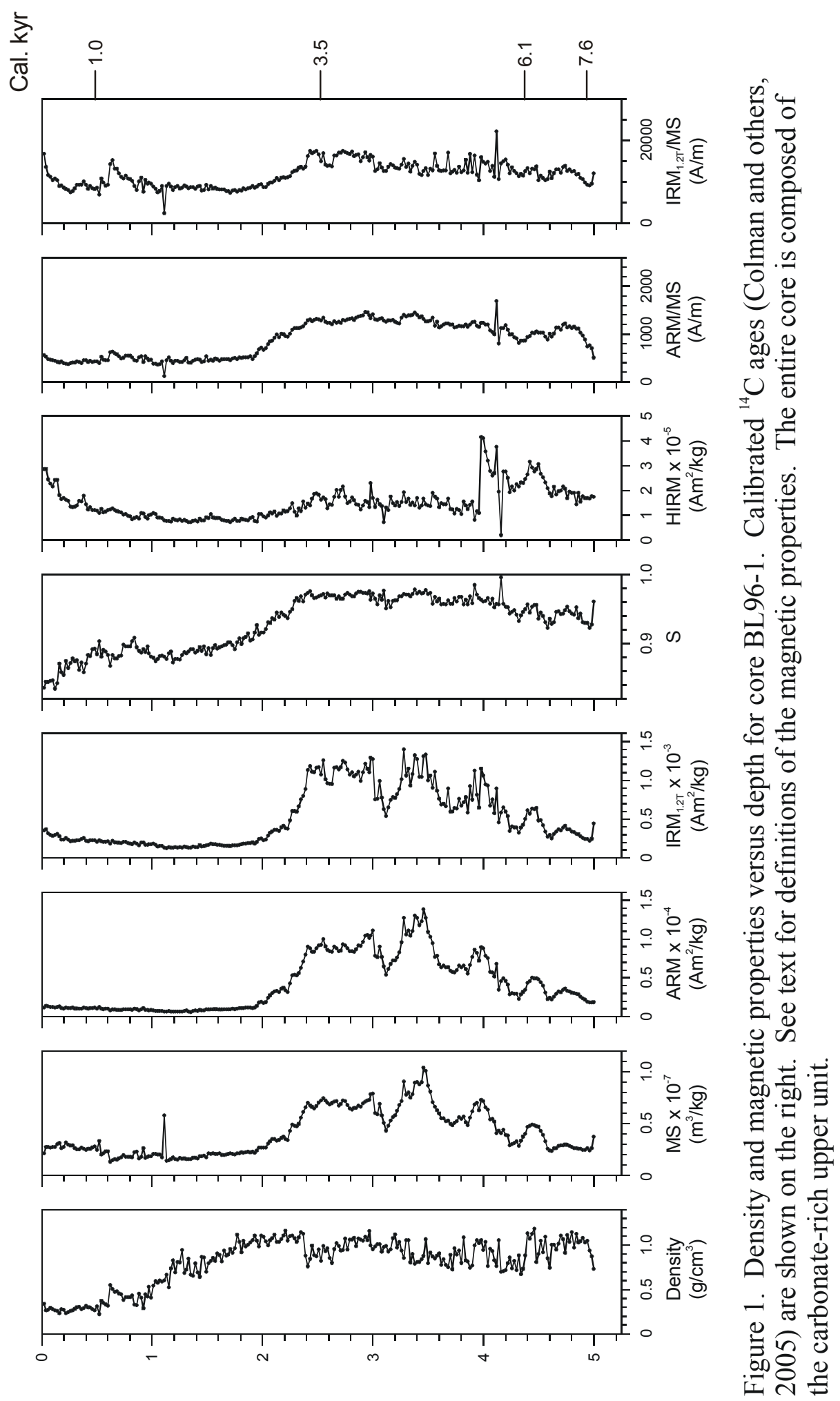

(sıәəәш) पłdə0 


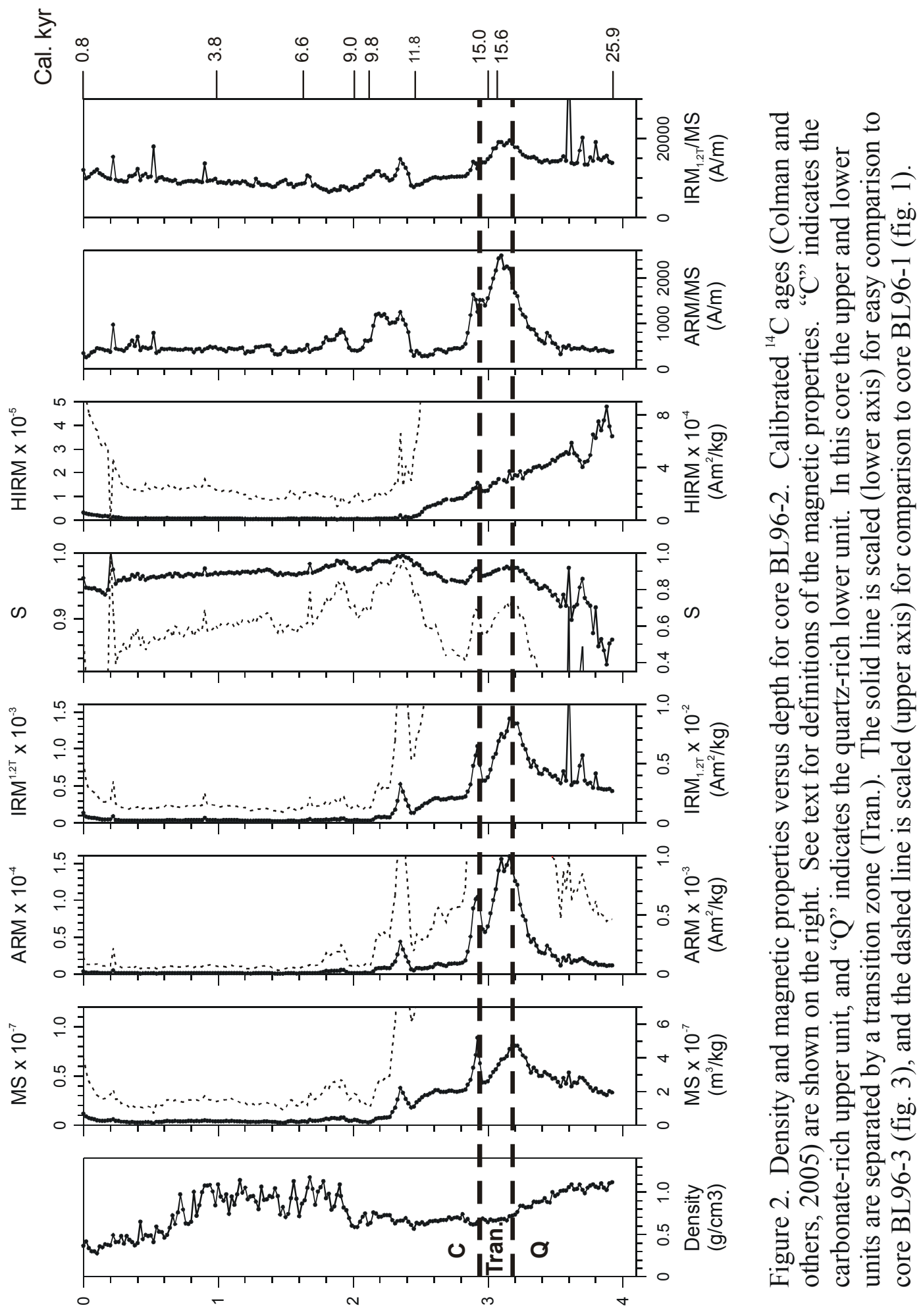

(sıәғәm) पłdə0 


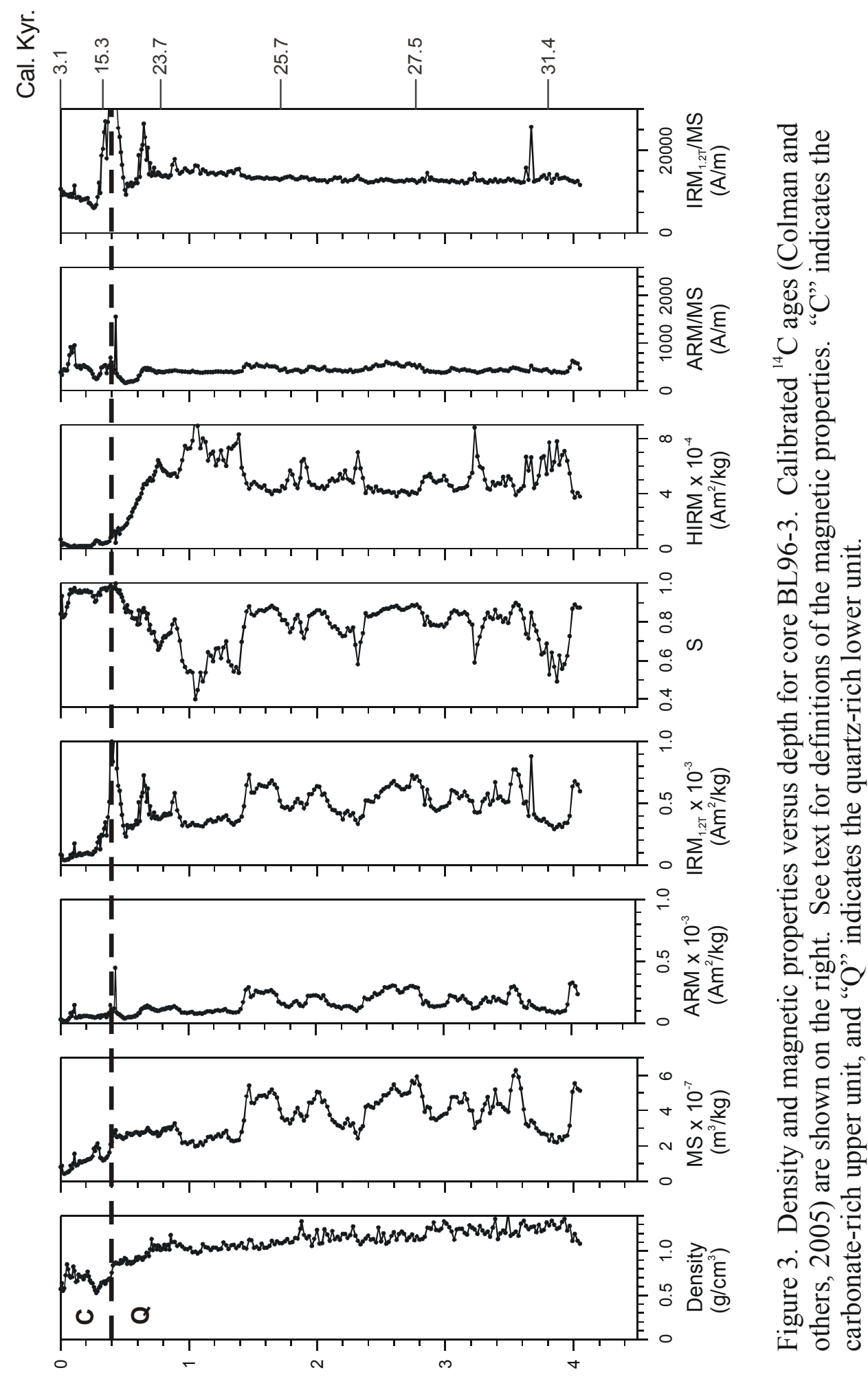

(sıәəәس) पұdə0 
Therefore, these variations are interpreted to reflect variable concentrations of two (or more) detrital components with contrasting magnetic properties.
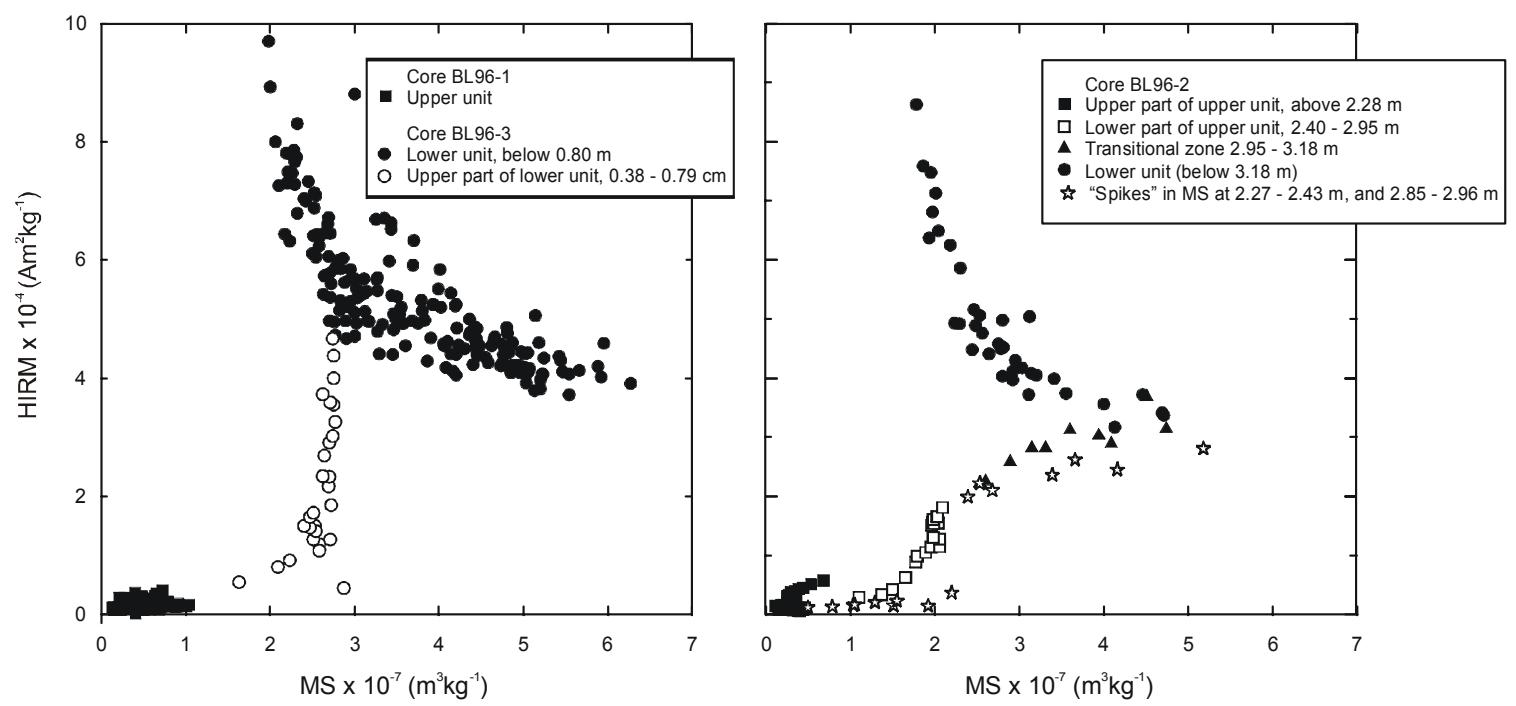

Figure 4. Hard isothermal remanent magnetization (HIRM) versus magnetic susceptibility (MS).

The upper part of the lower unit yields evidence of postdepositional alteration as well as changes in provenance. On the basis of HIRM values, the portion of the lower unit penetrated by core BL96-2 appears to correspond to the interval from 1.05 to $0.40 \mathrm{~m}$ in 96-3 (figs. 2 and 3). Peaks in HIRM at 3.88 and $3.62 \mathrm{~m}$ in core BL96-2 correlate, respectively, with peaks of similar magnitude at 1.05 and $0.76 \mathrm{~m}$ in core BL96-3. In core BL96-2, hematite (that is, HIRM) decreases by a factor of 2.5 from its peak at a depth of $3.88 \mathrm{~m}$ to the upper contact, and no abrupt change in magnetic properties occurs at the change in color near the top of the unit $(3.30 \mathrm{~m})$. Parameters indicative of magnetite content (for example, MS, ARM, and IRM) increase as hematite decreases (figs. 2 and 4), but in this case magnetic grain size decreases with increasing magnetite content (with ARM/MS displaying a much larger percentage change than IRM/MS). This suggests that in this part of the section, hematite-rich material is replaced by material relatively rich in magnetite, as in the older part of the lower unit previously discussed, but that in this instance the material may be derived from a different source area characterized by finer magnetic grain size. Similarly, above $0.65 \mathrm{~cm}$ in core BL96-3, HIRM decreases upward to the contact with the upper unit. However, the magnitude of HIRM at the contact in core BL96-3 is only about 30 percent of its magnitude at the contact in core BL 96-2. In core BL96-3, parameters indicative of magnetite do not vary in the manner observed in core BL96-2. MS and ARM do not increase toward the top of the unit, and prominent peaks in both IRM and IRM/MS are centered at 0.65 and $0.42 \mathrm{~m}$. The lower of these peaks spans the beginning of the color transition from reddish to yellowish sediments and the upper peak spans the top of the lower unit. The color of the uppermost sediments in core BL96-3, the lower values of HIRM, MS, and ARM near the top of the lower unit in 
comparison to the correlative part of the unit core BL96-2, and the high values of IRM/MS strongly suggest that iron oxides in this interval have undergone postdepositional alteration with concomitant formation of greigite. The presence of greigite in this zone has been verified by petrographic observations (R. Reynolds, USGS, written commun., 2005).

\section{Transition zone}

Much of the observed upward decrease in concentration parameters (MS, ARM, IRM, and HIRM in figure 2) within the transition zone between the lower and upper units can be attributed to dilution of detrital material by endogenic carbonate. Quartz (an approximate measure of the detrital component) decreases by a factor of about 2 (Dean and others, 2005), and the concentration parameters decrease by similar factors. ARM and IRM decrease by somewhat larger factors than MS, indicating that magnetic grain size increases across this zone (see ARM/MS and IRM/MS in figure 2). The grain-size change could indicate a change in the source of magnetite to an area with coarser magnetic grain size. A more likely explanation is that the upwards increase in grain size reflects the onset of postdepositional destruction of magnetite, with alteration increasing upwards into the lower part of the upper unit (as discussed in the following section).

\section{Upper unit}

In core BL96-2, the content of detrital material continues to decline upwards from the base of the upper unit but at a much slower rate than in the transition zone. Between the base of the upper unit (at $2.95 \mathrm{~m}$ ) and a depth of $2.00 \mathrm{~m}$, quartz content decreases by a factor of about 1.5 (Dean and others, 2005). Ignoring two sharply defined peaks in magnetite content (that is, peaks in MS, ARM and IRM; fig. 2) for the time being, the concentration parameters decline by factors of from 11 (for MS) to 25 (for ARM and HIRM) over this interval. The large decreases in the concentrations of both magnetite and hematite relative to the change in content of detrital material strongly suggest that iron oxides were destroyed postdepositionally. This interpretation is strengthened by the observation that magnetic grain size continues to increase upwards from the base of the upper unit (ARM/MS and IRM/MS in figure 2). Eight magnetic separates from the upper unit in cores BL96-1 and BL96-2 were studied petrographically (R. Reynolds, USGS, written commun., 2005). One sample, at 236 to $237 \mathrm{~cm}$ in core BL96-2 contains sparse magnetite in volcanic glass shards, suggesting that the upper peak in magnetite, which is centered at that depth, may be due to dispersed volcanic ash. The similarity in shape of the upper and lower peaks suggests similar origins, but no magnetic separate was studied from the lower peak.

Above $2.00 \mathrm{~m}$ in core BL96-2 concentration parameters remain low, and there is little variation to the top of the core. Much of this part of the upper unit corresponds to the section penetrated by core BL96-1. Concentration parameters in core BL96-1 are also low probably reflecting destruction of detrital iron oxides, but in contrast to core BL96-2 MS, ARM, and IRM have well-defined variations (fig. 1). These variations are highly correlated (fig. 5). 

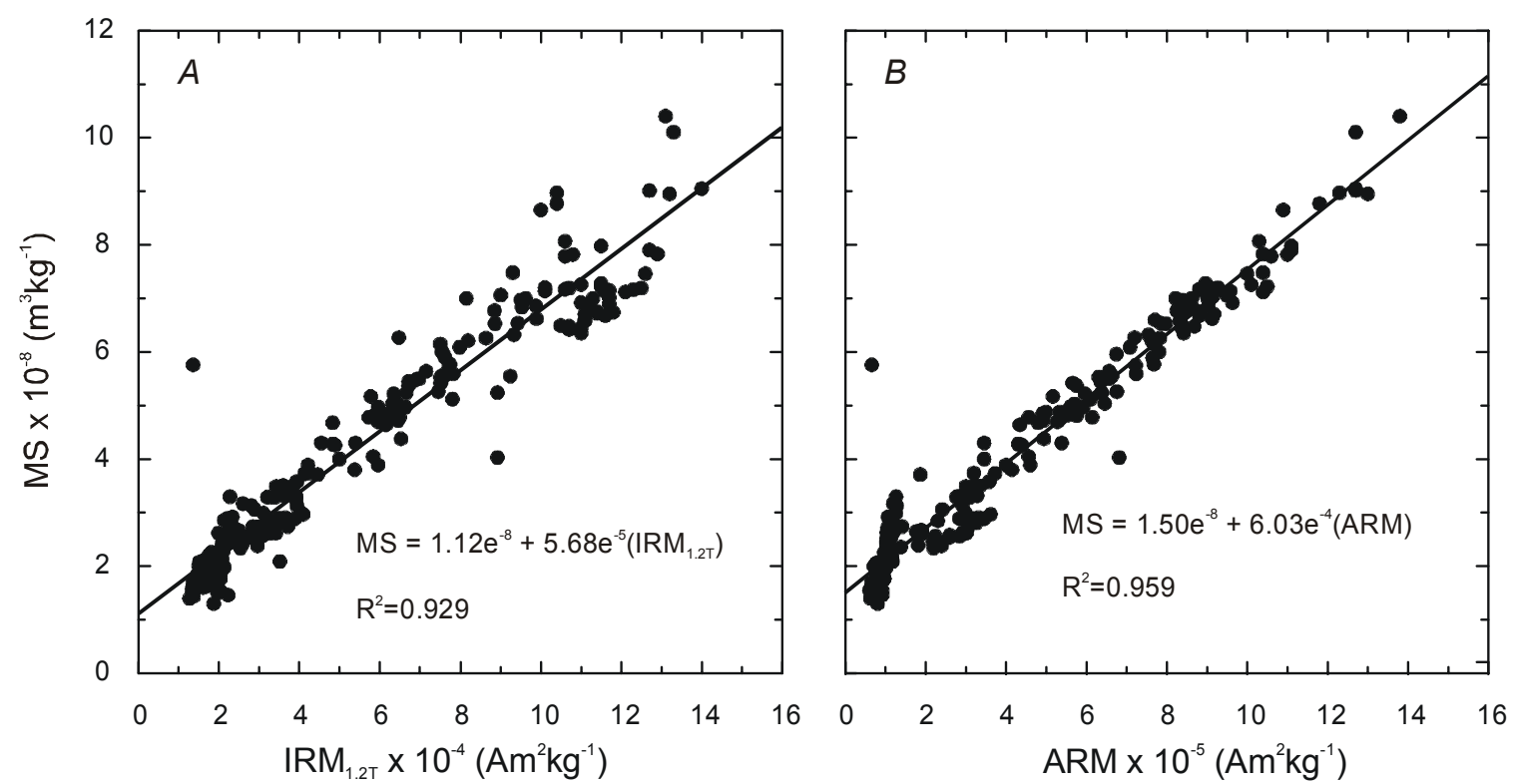

Figure 5. (A) Magnetic susceptibility (MS) versus isothermal remanent magnetization $\left(\mathrm{IRM}_{1.2 \mathrm{~T}}\right)$ and (B) MS versus anhysteretic remanent magnetization (ARM) for core BL96-1.

Two conclusions can be drawn from the strong linear relations between IRM and MS, and ARM and MS in core BL96-1. First, the non-zero intercepts indicate that paramagnetic minerals make a significant, relatively constant, contribution to the susceptibility. The average paramagnetic contribution appears to be a bit more than $1 \mathrm{x}$ $10^{-8} \mathrm{~m}^{3} \mathrm{~kg}^{-1}$. (For reference, the paramagnetic minerals pyrite and biotite have susceptibilities of $30 \times 10^{-8} \mathrm{~m}^{3} \mathrm{~kg}^{-1}$ and $80 \times 10^{-8} \mathrm{~m}^{3} \mathrm{~kg}^{-1}$, respectively.) Second, although there are systematic changes in ARM/MS and IRM/MS with magnetite content (fig. 1), these changes are not due to changes in magnetic grain size. Instead, these changes are due to variation in the relative contribution of an essentially constant amount of paramagnetic minerals to MS as the content of magnetite varies (that is, the relative contribution of paramagnetic minerals is large when the magnetite content is small). The origins of these variations in magnetite content are unclear, but they probably reflect varying preservation of detrital iron-oxide minerals. Similar variations do not occur in the apparently correlative part of the section sampled at the shallower site of core BL96-2 (fig. 2). It may be that the section penetrated by BL96-2 is discontinuous and lacks that part of the record that is correlative with the variable and generally somewhat elevated magnetite content in core BL96-1. This possibility is not supported by the radiocarbon ages. It is more likely that the difference in magnetic properties between the two sites reflects greater destruction of magnetite in core BL96-2 than in core BL96-1. Such a difference may reflect the difference in deposition rates between the two sites. For instance, destruction of iron oxides by sulfidization may cease when sediment has been buried to the point that diffusion can no longer replenish sulfate in the pore waters (Canfield and Berner, 1987). More rapid deposition at the site of core BL96-1 than at the 
site of core BL96-2, therefore, may favor greater preservation of detrital iron-oxide minerals.

\section{Summary}

1. Sediments sampled in three cores provide a composite record extending from the lastglacial period through the Holocene. Magnetic properties from a lower siliciclastic unit largely reflect detrital material, whereas those from a carbonate-rich upper unit largely reflect postdepositional destruction of iron oxide minerals.

2. Quasi-cyclical fluctuations in magnetic properties from the lower unit are produced by variations in the contents of sediment from two or more sources with contrasting magnetic properties.

3. Differences in magnetic properties between correlative sediments in the upper unit from cores BL96-1 and BL96-2 probably reflect differences in the degree of postdepositional destruction of iron-oxide minerals. The extent of alteration is in turn probably related to the rate of deposition, with slower deposition favoring greater destruction of detrital iron-oxide grains.

\section{Acknowledgements}

Cores were collected under the direction of K. Kelts using a Kullenberg corer belonging to the University of Minnesota. Magnetic property measurements were made by W. Rivers. Constructive reviews were provided by H. Goldstein and G. Skipp.

Funding for this study was provided by the Earth Surface Dynamics Program of the U.S. Geological Survey.

\section{References Cited}

Canfield, D.E., and Berner, R.A., 1987, Dissolution and pyritization of magnetite in anoxic marine sediments: Geochimica et Cosmochimica Acta, v. 51, p. 645-659.

Colman, S., 2005, Stratigraphy of lacustrine sediments cored in 1996, Bear Lake, Utah and Idaho: U.S. Geological Survey Open-File Report \#\#\#.

Colman, S., Kaufman, D., Rosenbaum, J.G., and McGeehin, J.P., 2005, Radiocarbon dating of cores collected from Bear Lake, Utah and Idaho: U.S. Geological Survey Open-File Report \#\#\#.

Dean, W., Forester, R., Colman, S., Liu, A., Skipp, G., Simmons, K., Swarzenski, P., Anderson, R., and Thornburg, D., 2005, Modern and glacial-Holocene carbonate sedimentation in Bear Lake, Utah and Idaho: U.S. Geological Survey Open-File Report 2005-1124.

Dunlop, D., and Özdemir, Ö., 1997, Rock magnetism-fundamentals and frontiers: New York, NY, Cambridge University Press, 573 p. 
King, J.W., and Channel, J.E.T., 1991, Sedimentary magnetism, environmental magnetism, and magnetostratigraphy: Reviews of Geophysics, Supplement, $\mathrm{p}$. $358-370$

Reynolds, R.L., Rosenbaum, J.G., Mazza, N., Rivers, W., and Luiszer, F., 1998, Sediment magnetic data ( 83 to $18 \mathrm{~m}$ depth) and XRF geochemical data ( 83 to 32 $m$ depth) from lacustrine sediment in core OL-92 from Owens Lake, California: U.S. Geological Survey Open-File Report 98-132, 34 p.

Reynolds, R.L., Rosenbaum, J.G., van Metre, P., Tuttle, M., Callender, E., and Goldin, A., 1999, Greigite $\left(\mathrm{Fe}_{3} \mathrm{~S}_{4}\right)$ as an indicator of drought-the 1912-1994 sediment magnetic record from White Rock Lake, Dallas, Texas, USA: Journal of Paleolimnology, v. 21, p. 193-206.

Rosenbaum, J.G., and Reynolds, R.L., 2004, Basis for paleoenvironmental interpretation of magnetic properties of sediment from Upper Klamath Lake (Oregon)-effects of weathering and mineralogical sorting: Journal of Paleolimnology, v. 31, p. 253-265.

Smoot, J., 2005, Sedimnetary features in cores BL96-1, -2, -3, Bear Lake, Utah and Idaho: U.S. Geological Survey Open-File Report \#\#\#.

Thompson, R., and Oldfield, F., 1986, Environmental magnetism: London, Allen \& Unwin, $227 \mathrm{p}$.

Verosub, K.L., and Roberts, A.P., 1995, Environmental magnetism-past, present and future: Journal of Geophysical Research, v. 100, p. 2175-2192. 